\title{
Survival rates are higher in married patients with biliary tract cancer: a population-based study
}

\author{
Wei Song ${ }^{1, *}$, Dong-Liu Miao ${ }^{1, *}$ and Lei Chen ${ }^{1}$ \\ ${ }^{1}$ Department of Intervention and Vascular Surgery, Affiliated Suzhou Hospital of Nanjing Medical University, Suzhou Municipal \\ Hospital, Suzhou Cancer Medical Center, Suzhou, China \\ "These authors contributed equally to this work
}

Correspondence to: Lei Chen, email: 13771775313@163.com

Keywords: biliary tract cancer; marital status; SEER; survival analysis; prognosis

Received: July 27, 2017

Accepted: December 05, 2017

Published: January 11, 2018

Copyright: Song et al. This is an open-access article distributed under the terms of the Creative Commons Attribution License 3.0 (CC BY 3.0), which permits unrestricted use, distribution, and reproduction in any medium, provided the original author and source are credited.

\section{ABSTRACT}

Marital status has been identified as a prognostic factor in multiple malignancies. In this study, we assessed the prognostic value of marital status in 24,035 patients from the Surveillance, Epidemiology, and End Results database diagnosed with biliary tract cancer (BTC) between 2004 and 2014. Widowed patients were more likely to be women, elderly ( $>60$ years), have gallbladder cancer, and have localized SEER Stage disease than all other patients. Marital status was identified as an independent prognostic factor in both univariate and multivariate analyses, and cause-specific survival (CSS) rates were higher in married patients than unmarried patients. In addition, CSS rates were higher in ampulla of Vater cancer patients than in gallbladder cancer or cholangiocarcinoma patients. Further analysis revealed that CSS rates were lowest in widowed patients at each TNM stage and for all tumor sites. These results suggest marital status is a prognostic factor for clinical outcomes in patients with BTC, and widowed patients are at greater risk of cancer-specific mortality.

\section{INTRODUCTION}

Biliary tract cancer (BTC) is a category of tumors that includes gallbladder cancer (GBC), cholangiocarcinoma, and ampullary cancer $[1,2]$. Although BTC is rare, its incidence is increasing worldwide [3, 4]. In Japan, BTC is the sixth leading cause of cancer-related death, and more than 18,000 patients die from the disease annually [5]. Radical resection remains the only curative treatment for BTC, and recurrence rates after resection are high $[6,7]$. Moreover, because BTC is usually diagnosed at an advanced stage, most patients are not considered candidates for curative resection. Despite recent improvements in surgical techniques and adjuvant therapy, the overall prognosis of BTC remains poor $[8$, 9]. It is therefore vital to identify factors that predict prognosis in BTC patients to help clinicians implement better therapeutic strategies.

Studies have identified a positive correlation between marital status and survival in BTC patients, and married people are healthier overall and live longer than unmarried people (divorced, separated, never married) [10-12]. In a large study of multiple cancer treatment sites, married patients were more likely to present with early stage disease upon diagnosis and to receive definitive treatment compared to unmarried patients [13]. Being married is also positively associated with overall and cancer-related survival for various types of cancer, such as hepatocellular carcinoma [14], breast cancer [15], gastric adenocarcinoma [16], and pancreatic cancer [17]. According to a larger-scale population-based study of information from the Surveillance, Epidemiology, and End Results (SEER) database, unmarried patients are at significantly higher risk of presentation with metastatic cancer, undertreatment, and cancer-related death [13]. However, little is known about the association between marital status and BTC. In this study, we investigated the association between marital status and cause-specific survival (CSS) in BTC patients by examining data from the Surveillance, Epidemiology, and End Results (SEER) cancer registry program for individuals diagnosed between 2004 and 2014. 


\section{MATERIALS AND METHODS}

\section{Patient population and study design}

The Surveillance, Epidemiology, and End Results (SEER) Program of the US National Cancer Institute (NCI) was used as the data source for this populationbased investigation. The SEER Program captures approximately $97 \%$ of incident cancers, and the 17 SEER tumor registries encompass approximately $28 \%$ of the US population [18]. The SEER Program collects information on cancer incidence, prevalence, survival, and cancer patient mortality.

We used the SEER Program to identify 24035 patients who were diagnosed with biliary tract cancer between 2004 and 2014. Patients with a diagnosis of biliary tract cancer (International Classification of Diseases for Oncology, Third Edition [ICD-O-3], histology codes 8010, 8020, 8040, 8041, 8070, 8140, $8144,8160,8161,8162,8260,8310,8480,8490$, and 8560 , and site codes C23.0, C23.9, C22.1, C24.0, and $\mathrm{C} 24.1$ ) were considered for analysis. Patients more than 18 years old for whom marital status, cause of death, and survival duration in months were known were included in the current study. Patients with multiple primary cancers were excluded if BTC was not the first disease diagnosed.

This study was based on public data from the SEER database; we obtained permission to access research data files (reference number 10091-Nov 2016). The data did not include the use of human subjects or personal identifying information; thus, informed consent was not required.

\section{Study variables}

Several variables, including demographics (sex, age, race), TNM stage, extent of disease (localized, regional, distant), tumor site (gallbladder cancer and cholangiocarcinoma, ampulla of Vater cancer), tumor grade (well-differentiated, moderately differentiated, poorly differentiated, undifferentiated, unknown), histologic type, treatment, and marital status at the time of diagnosis were examined. Marital status, the major variable of interest, was classified in a binary manner (married vs unmarried). The unmarried category included widowed and separated/divorced patients as well as those who never married. The AJCC 6th TNM staging system was used; because this staging system became publicly available in 2004, we restricted our study to patients diagnosed from 2004-2014. According to the SEER staging system, tumors that remain in situ, or confined to the organ of origin, were considered localized. Those with local invasion or metastasis to regional lymph nodes were categorized as regional, while those with cancer that traveled to distant organs were categorized as distant.

\section{Statistical analyses}

Baseline patient demographics and disease characteristics were compared using $t$-tests or chi-square tests as appropriate. The Kaplan-Meier method was used to assess survival functions. The log rank test was used to test differences between survival curves. Cox proportional hazards multivariable regression was used to assess the impact of marital status on cancer-specific mortality. The primary outcomes of interest in this study was 5-year CSS, which was calculated from the date of diagnosis to the date of cancer-specific death. Deaths attributed to BTC were treated as events, while deaths from other causes were treated as censored observations. All $P$ values were 2 -sided, and $P$ values $<0.05$ were considered statistically significant. All statistical analyses were performed using SPSS version 23 (Statistics Package for Social Science, Chicago, IL).

\section{RESULTS}

\section{Patient characteristics}

A total of 24035 qualified patients who were diagnosed during the 10-year study period (2004 to 2014) were identified. Of these patients, 10774 (44.8\%) were male and $13261(55.2 \%)$ were female. $13268(55.2 \%)$ were married, 5062 (21.1\%) were widowed, 3347 (13.9\%) had never married, and 2358 (9.8\%) were divorced or separated. Higher proportions of patients in the widowed group were women, elderly ( $>60$ years), had gallbladder cancer, and had more localized SEER Stage disease compared to all other patients (all $p<0.001$ ). Patient demographics and pathological features are shown in Table 1.

\section{Effect of marital status on CSS}

Married patients had higher 5-year CSS than unmarried patients $(18.7 \%$ vs $15.2 \%)(P<0.001)$ (Figure 1). Five-year CSS was $18.7 \%$ in the married group, $13.9 \%$ in the widowed group, $17.9 \%$ in the never married group, and $14.4 \%$ in the divorced/separated group; a univariate $\log$ rank test revealed that CSS differed significantly among all groups $(P<0.001)$ (Figure $2 \mathrm{~A})$. Additionally, elderly patients $(P<0.001)$, black patients $(P<0.001)$, patients with cholangiocarcinoma $(P<0.001)$, TNM stage III/IV $(P<0.001)$, poorly or undifferentiated tumors $(P<$ $0.001)$, or advanced SEER stage $(P<0.001)$, and patients who did not undergo surgery $(P<0.001)$ were at higher risk of poor survival in a univariate analysis (Table 2).

The following eight variables were identified as independent prognostic factors in multivariate analysis with Cox regression: age ( $>60$ years, hazard ratio (HR) 1.388, 95\% confidence interval (CI) 1.338-1.441), race (other, HR $0.896,95 \%$ CI $0.856-0.938$ ), tumor site (bile duct, HR 
Table 1: Baseline demographic and tumor characteristics of SEER database patients

\begin{tabular}{|c|c|c|c|c|c|c|}
\hline & Total & Married & Widowed & $\begin{array}{l}\text { Never } \\
\text { married }\end{array}$ & $\begin{array}{l}\text { Divorced/ } \\
\text { Separated }\end{array}$ & $P$ \\
\hline Characteristic & $(n=24035)$ & $(n=13268)$ & $(n=5062)$ & $(n=3347)$ & $(n=2358)$ & \\
\hline & $N$ & $N(\%)$ & $N(\%)$ & $N(\%)$ & $N(\%)$ & \\
\hline Sex & & & & & & $<0.001$ \\
\hline Male & 10774 & $7396(55.7)$ & $898(17.7)$ & $1530(45.7)$ & $950(40.3)$ & \\
\hline Female & 13261 & $5872(44.3)$ & $4164(82.3)$ & $1817(54.3)$ & $1408(59.7)$ & \\
\hline Age & & & & & & $<0.001$ \\
\hline$\leq 60$ & 6314 & $3866(29.1)$ & $210(4.1)$ & $1452(43.4)$ & $786(33.3)$ & \\
\hline$>60$ & 17721 & $9402(70.9)$ & 4852 (95.9) & $1895(56.6)$ & $1572(66.7)$ & \\
\hline Race & & & & & & $<0.001$ \\
\hline White & 18478 & $10302(77.6)$ & 3935 (76.4) & $2405(73.8)$ & $1836(77.9)$ & \\
\hline Black & 2270 & $886(6.7)$ & $579(11.2)$ & $489(15.0)$ & $316(13.4)$ & \\
\hline Other $^{*}$ & 3287 & $2080(15.7)$ & $638(12.4)$ & $363(11.1)$ & $206(8.7)$ & \\
\hline Tumor site & & & & & & $<0.001$ \\
\hline Gallbladder & 7869 & $4014(30.3)$ & $1938(38.3)$ & $1120(33.5)$ & $797(33.8)$ & \\
\hline Bile duct & 12668 & $7176(54.1)$ & $2503(49.4)$ & $1748(52.2)$ & $1241(52.6)$ & \\
\hline Ampulla of Vater & 3498 & $2078(15.7)$ & $621(12.3)$ & $479(14.3)$ & $320(13.6)$ & \\
\hline AJCC 6th TNM stage & & & & & & $<0.001$ \\
\hline I & 5205 & $2842(22.2)$ & $1224(22.0)$ & $675(20.2)$ & $464(19.7)$ & \\
\hline II & 5109 & $2974(23.3)$ & $938(16.9)$ & $690(20.6)$ & $507(21.5)$ & \\
\hline III & 2715 & $1627(12.7)$ & $432(7.8)$ & $356(10.6)$ & $300(12.7)$ & \\
\hline IV & 7521 & $4239(33.2)$ & $1373(24.7)$ & $1117(33.4)$ & $792(33.6)$ & \\
\hline Unknown & 3485 & $1095(8.6)$ & $1586(28.6)$ & $509(15.2)$ & $295(12.5)$ & \\
\hline Grade & & & & & & $<0.001$ \\
\hline I & 1702 & $985(7.4)$ & $334(6.6)$ & $237(7.1)$ & $146(6.2)$ & \\
\hline II & 5891 & $3443(25.9)$ & 1059 (20.9) & $819(24.5)$ & $570(24.2)$ & \\
\hline III & 5139 & $3006(22.7)$ & $943(18.6)$ & $682(20.4)$ & $508(21.5)$ & \\
\hline IV & 220 & $125(0.9)$ & $52(1.0)$ & $26(0.8)$ & $17(0.7)$ & \\
\hline Unknown & 11083 & $5709(43.0)$ & $2674(52.8)$ & $1583(47.3)$ & $1117(47.4)$ & \\
\hline SEER Stage & & & & & & $<0.001$ \\
\hline Localized & 5526 & $2870(21.6)$ & $1390(27.5)$ & $757(22.6)$ & $509(21.6)$ & \\
\hline Regional & 7853 & $4680(35.3)$ & $1370(27.1)$ & $1051(31.4)$ & 752 (31.9) & \\
\hline Distant & 8367 & $4743(35.7)$ & $1504(29.7)$ & $1227(36.7)$ & 893 (37.9) & \\
\hline Unknown & 2289 & $975(7.3)$ & $798(15.8)$ & $312(9.3)$ & $204(8.7)$ & \\
\hline Therapy & & & & & & $<0.001$ \\
\hline Surgery & 10169 & 6046 (45.6) & $1788(35.3)$ & $1353(40.4)$ & 982 (41.6) & \\
\hline No surgery & 13629 & 7107 (53.6) & 3207 (63.4) & $1962(58.6)$ & $1353(57.4)$ & \\
\hline Unknown & 237 & $115(0.9)$ & $67(1.3)$ & $32(1.0)$ & $23(1.0)$ & \\
\hline
\end{tabular}

*: Other includes American Indian/Alaska native, Asian/Pacific Islander, and unknown. 
Table 2: Univariate and multivariate survival analysis of associations between marital status and CSS in SEER database patients

\begin{tabular}{|c|c|c|c|c|c|}
\hline \multirow[b]{2}{*}{ Variable } & \multirow[b]{2}{*}{ 5-year CCS } & \multicolumn{2}{|c|}{ Univariate analysis } & \multicolumn{2}{|c|}{ Multivariate analysis } \\
\hline & & Log rank $\chi^{2}$ test & $P$ & HR $(95 \%$ CI) & $P$ \\
\hline Sex & & 0.480 & 0.488 & & NI \\
\hline Male & $17.0 \%$ & & & & \\
\hline Female & $17.2 \%$ & & & & \\
\hline Age & & 271.377 & $<0.001$ & & \\
\hline$\leq 60$ & $20.9 \%$ & & & Reference & \\
\hline$>60$ & $15.7 \%$ & & & $1.388(1.338-1.441)$ & $<0.001$ \\
\hline Race & & 39.979 & $<0.001$ & & \\
\hline White & $16.9 \%$ & & & Reference & \\
\hline Black & $15.2 \%$ & & & $1.049(0.995-1.105)$ & 0.77 \\
\hline Other* & $19.7 \%$ & & & $0.896(0.856-0.938)$ & $<0.001$ \\
\hline Tumor site & & 1197.390 & $<0.001$ & & \\
\hline Gallbladder & $19.6 \%$ & & & Reference & \\
\hline Bile duct & $10.5 \%$ & & & $0.847(0.815-0.881)$ & $<0.001$ \\
\hline Ampulla of Vater & $34.6 \%$ & & & $0.569(0.538-0.602)$ & $<0.001$ \\
\hline AJCC 6th TNM stage & & 4995.646 & $<0.001$ & & \\
\hline I & $41.4 \%$ & & & Reference & \\
\hline II & $21.2 \%$ & & & $1.553(1.446-1.668)$ & $<0.001$ \\
\hline III & $13.3 \%$ & & & $1.652(1.525-1.789)$ & $<0.001$ \\
\hline IV & $2.0 \%$ & & & $2.225(2.007-2.466)$ & $<0.001$ \\
\hline Unknown & $8.1 \%$ & & & $1.969(1.816-2.135)$ & $<0.001$ \\
\hline Grade & & 2945.362 & $<0.001$ & & \\
\hline I & $41.4 \%$ & & & Reference & \\
\hline II & $28.7 \%$ & & & $1.275(1.180-1.377)$ & $<0.001$ \\
\hline III & $15.6 \%$ & & & $1.761(1.630-1.902)$ & $<0.001$ \\
\hline IV & $17.1 \%$ & & & $1.631(1.372-1.939)$ & $<0.001$ \\
\hline Unknown & $7.4 \%$ & & & $1.461(1.353-1.577)$ & $<0.001$ \\
\hline SEER Stage & & 3717.179 & $<0.001$ & & \\
\hline Localized & $34.9 \%$ & & & Reference & \\
\hline Regional & $21.1 \%$ & & & $1.118(1.047-1.193)$ & $<0.001$ \\
\hline Distant & $3.3 \%$ & & & $1.212(1.101-1.334)$ & $<0.001$ \\
\hline Unknown & $7.8 \%$ & & & $1.000(0.917-1.091)$ & $<0.001$ \\
\hline Therapy & & 5505.595 & $<0.001$ & & \\
\hline Surgery & $33.3 \%$ & & & Reference & \\
\hline No surgery & $4.1 \%$ & & & $2.448(2.336-2.566)$ & $<0.001$ \\
\hline Unknown & $9.0 \%$ & & & $1.962(1.687-2.283)$ & $<0.001$ \\
\hline Marital Status & & 284.788 & $<0.001$ & & \\
\hline Married & $18.7 \%$ & & & Reference & \\
\hline Widowed & $13.9 \%$ & & & $1.245(1.196-1.295)$ & $<0.001$ \\
\hline Never married & $17.9 \%$ & & & $1.142(1.090-1.197)$ & $<0.001$ \\
\hline Divorced/Separated & $14.4 \%$ & & & $1.135(1.077-1.196)$ & $<0.001$ \\
\hline
\end{tabular}

"Other includes American Indian/Alaska native, Asian/Pacific Islander, and unknown. NI: not included in the multivariate survival analysis. 
Table 3: Univariate and multivariate analysis of associations between marital status and CSS for different cancer stages

\begin{tabular}{|c|c|c|c|c|c|}
\hline \multirow[b]{2}{*}{$\begin{array}{l}\text { AJCC 6th TNM stage/ } \\
\text { Variable }\end{array}$} & \multirow[b]{2}{*}{ 5-year CCS } & \multicolumn{2}{|c|}{ Univariate analysis } & \multicolumn{2}{|c|}{ Multivariate analysis } \\
\hline & & Log rank $\chi^{2}$ test & $P$ & HR $(95 \%$ CI $)$ & $P$ \\
\hline Stage I & & 42.865 & $<0.001$ & & \\
\hline Marital status & & & & & $<0.001$ \\
\hline Married & $43.8 \%$ & & & Reference & \\
\hline Widowed & $35.9 \%$ & & & $1.369(1.244-1.506)$ & $<0.001$ \\
\hline Never married & $42.4 \%$ & & & $1.089(0.962-1.234)$ & 0.178 \\
\hline Divorced/Separated & $39.9 \%$ & & & $1.119(0.971-1.290)$ & 0.119 \\
\hline Stage II & & 92.511 & $<0.001$ & & \\
\hline Marital status & & & & & 0.001 \\
\hline Married & $23.5 \%$ & & & Reference & \\
\hline Widowed & $14.6 \%$ & & & $1.522(1.393-1.664)$ & $<0.001$ \\
\hline Never married & $23.7 \%$ & & & $1.153(1.037-1.282)$ & 0.009 \\
\hline Divorced/Separated & $17.1 \%$ & & & $1.213(1.080-1.363)$ & 0.001 \\
\hline Stage III & & 48.252 & $<0.001$ & & \\
\hline Marital status & & & & & $<0.001$ \\
\hline Married & $14.3 \%$ & & & Reference & \\
\hline Widowed & $8.8 \%$ & & & $1.504(1.330-1.701)$ & $<0.001$ \\
\hline Never married & $18.4 \%$ & & & $0.983(0.850-1.136)$ & 0.813 \\
\hline Divorced/Separated & $8.8 \%$ & & & $1.152(0.996-1.332)$ & 0.056 \\
\hline Stage IV & & 145.801 & $<0.001$ & & \\
\hline Marital status & & & & & $<0.001$ \\
\hline Married & $2.4 \%$ & & & Reference & \\
\hline Widowed & $1.2 \%$ & & & $1.447(1.355-1.545)$ & $<0.001$ \\
\hline Never married & $1.2 \%$ & & & $1.172(1.090-1.260)$ & $<0.001$ \\
\hline Divorced/Separated & $2.0 \%$ & & & $1.144(1.054-1.242)$ & 0.001 \\
\hline
\end{tabular}

0.847, 95\% CI 0.815-0.881; ampulla of Vater, HR 0.569, 95\% CI 0.538-0.602), TNM stage (stage II, HR 1.553, 95\% CI 1.446-1.668; stage III, HR 1.652, 95\% CI 1.525-1.789; stage IV, HR 2.225, 95\% CI 2.007-2.466), pathological grade (grade II, HR 1.275, 95\% CI 1.180-1.377; grade III, HR 1.761, 95\% CI 1.630-1.902; grade IV, HR 1.631, 95\% CI 1.372-1.939), SEER stage (regional, HR 1.118, 95\% CI 1.047-1.193; distant, HR 1.212, 95\% CI 1.101-1.334), therapy (no surgery, HR 2.448, 95\% CI 2.336-2.566), and marital status (widowed, HR 1.245, 95\% CI 1.196-1.295; never married, HR 1.142, 95\% CI 1.090-1.197; divorced/ separated, HR 1.135, 95\% CI 1.077-1.196).

\section{Subgroup analysis of associations between marital status and survival for different TNM stages}

We then analyzed the relationship between marital status and survival at each TNM stage. Marital status was an independent prognostic factor in each tumor stage both in univariate and multivariate analyses $(P<0.05)$. In addition, widowed patients in the localized stage group had lower survival rates than all other patients. Five-year CSS was reduced by $7.9 \%$ in stage I $(35.9 \%$ vs $43.8 \%, P$ $<0.001), 8.9 \%$ in stage II (14.6\% vs $23.5 \%, P<0.001)$, $5.5 \%$ in stage III $(8.8 \%$ vs $14.3 \%, P<0.001)$, and $1.2 \%$ in stage IV $(1.2 \%$ vs $2.4 \%, P<0.001)$ widowed patients compared to married patients with the same stages. Finally, 5-year CSS rates did not differ between never married and married patients with either regional or distant stage disease (Table 3, Figure 2B-2D).

\section{Subgroup analysis of associations between marital status and survival for different tumor sites}

We also analyzed the association between marital status and survival for each tumor site. Marital status was 
Table 4: Univariate and multivariate analysis of associations between marital status and CSS for different tumor sites

\begin{tabular}{|c|c|c|c|c|c|}
\hline \multirow[b]{2}{*}{ Tumor site/Variable } & \multirow[b]{2}{*}{ 5-year CCS } & \multicolumn{2}{|c|}{ Univariate analysis } & \multicolumn{2}{|c|}{ Multivariate analysis } \\
\hline & & Log rank $\chi^{2}$ test & $P$ & HR (95\% CI) & $P$ \\
\hline Gallbladder & & 32.220 & $<0.001$ & & \\
\hline Marital status & & & & & $<0.001$ \\
\hline Married & $20.4 \%$ & & & Reference & \\
\hline Widowed & $18.6 \%$ & & & $1.195(1.119-1.276)$ & $<0.001$ \\
\hline Never married & $19.4 \%$ & & & $1.120(1.033-1.215)$ & 0.006 \\
\hline Divorced/Separated & $18.6 \%$ & & & $1.075(0.981-1.178)$ & 0.122 \\
\hline Bile duct & & 257.23 & $<0.001$ & & \\
\hline Marital status & & & & & $<0.001$ \\
\hline Married & $12.0 \%$ & & & Reference & \\
\hline Widowed & $7.1 \%$ & & & $1.480(1.406-1.558)$ & $<0.001$ \\
\hline Never married & $11.4 \%$ & & & $1.137(1.069-1.209)$ & $<0.001$ \\
\hline Divorced/Separated & $7.1 \%$ & & & $1.247(1.165-1.335)$ & $<0.001$ \\
\hline Ampulla of Vater & & 60.189 & $<0.001$ & & \\
\hline Marital status & & & & & $<0.001$ \\
\hline Married & $37.2 \%$ & & & Reference & \\
\hline Widowed & $25.7 \%$ & & & $1.574(1.399-1.770)$ & $<0.001$ \\
\hline Never married & $36.8 \%$ & & & $1.075(0.934-1.239)$ & 0.313 \\
\hline Divorced/Separated & $31.5 \%$ & & & $1.108(0.942-1.305)$ & 0.216 \\
\hline
\end{tabular}

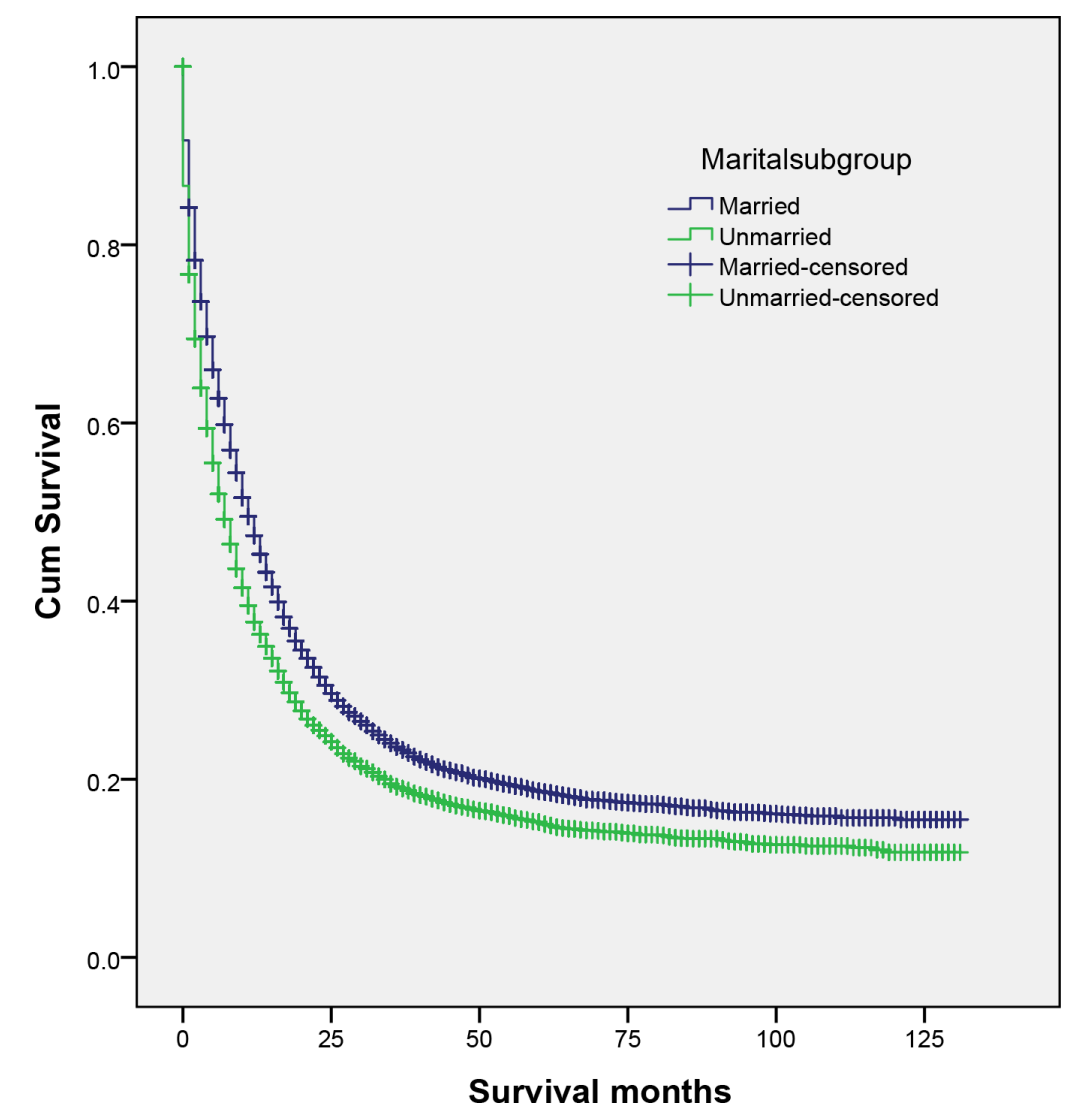

Figure 1: Survival curves for married and unmarried biliary tract cancer patients. $\chi^{2}=205.491, P<0.001$. 
again predictive of CSS in univariate and multivariate analyses $(p<0.05)$. CSS rates were higher in Ampulla of Vater cancer patients than in gallbladder cancer and cholangiocarcinoma patients. Widowed individuals still had the lowest survival rate among all patients (Table 4).

\section{DISCUSSION}

In this study, we investigated associations between marriage and CSS in a large BTC patient population. We found that married patients have better cause-specific survival outcomes than unmarried patients, which includes widowed and separated/divorced patients and those who never married. This association between being married and better survival persisted even after adjusting for age, race, tumor site, pathology grade, TNM stage, SEER stage, and therapy in multivariable analyses. Moreover, widowed patients had a higher risk of cause-specific death than all other patient groups. Further subgroup analyses based on TNM stage and tumor site confirmed the prognostic value of marital status in BTC patients.

Previous studies have suggested that poorer prognoses in unmarried individuals may be due to delayed diagnosis at more advanced tumor stages in these patients $[13,19,20]$. However, in our patient population, the percentages of patients at each tumor stage were comparable among the four marriage status subgroups. Moreover, a higher proportion of widowed group patients $(27.5 \%)$ had localized stage disease compared to married $(21.6 \%)$, never married $(22.6 \%)$, and divorced/separated $(21.6 \%)$ group patients. These results suggest that delayed diagnosis cannot explain the poorer survival outcomes observed in widowed patients.

The exact mechanisms underlying the prognostic impact of marital status in GBC are unclear. Several biological, psychological, and social theories have been postulated to explain this phenomenon. It is well known that a diagnosis of cancer is psychologically distressing for most patients [21]. Because they do not have spouses to share their emotional burdens and contribute to their social support networks, unmarried cancer patients may experience more distress, depression, and anxiety than married patients [22, 23]. Additionally, marital status may affect adherence to prescribed treatments. Compared to unmarried patients, married patients are more likely to comply with treatment, to seek treatment at more prestigious centers, and to accept more aggressive treatment, all of which may contribute to better cancer control [24, 25].

Physiological changes accompanying stress and depression may worsen cancer outcomes through different mechanisms. For example, decreased psychosocial support
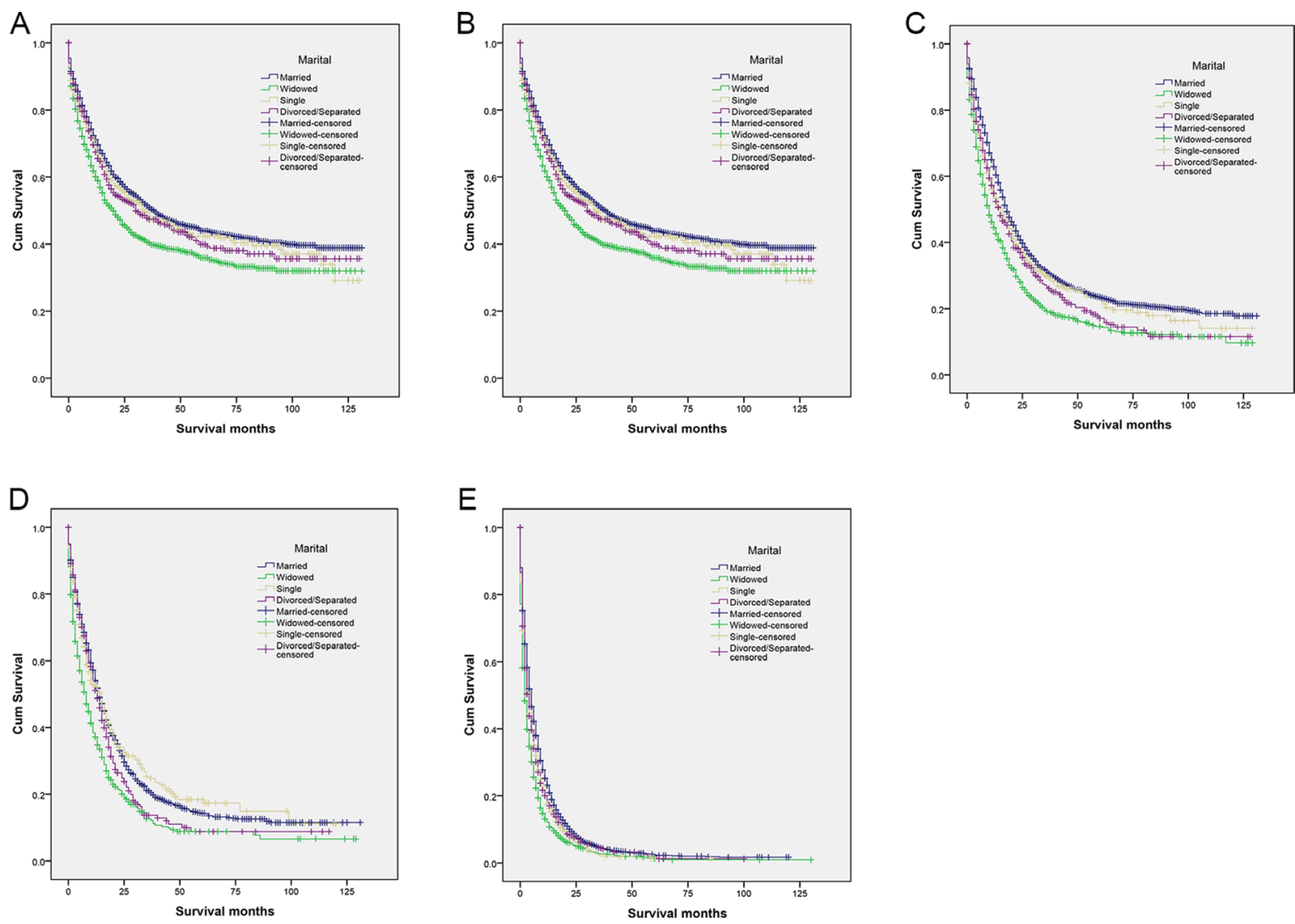

Figure 2: Survival curves for married and unmarried biliary tract cancer patients by stage. (A) All stages: $\chi^{2}=23225.337$, $P<0.001$ (B) Stage I: $\chi^{2}=42.865, P<0.001$ (C) Stage II: $\chi^{2}=92.511, P<0.001$ (D) Stage III: $\chi^{2}=48.252, P<0.001$ (E) Stage IV: $\chi^{2}=$ 145.801, $P<0.001$. 
and increased psychological stress result in immune dysfunction and contribute to tumor progression and mortality [26-28]. Furthermore, perceived lack of social support can reduce the activity of natural killer cells [29], resulting in dysregulation of various endocrine hormones, such as cortisol and catecholamines [26, 28]. Several studies demonstrate that cortisol and catecholamines can accelerate cancer growth and metastasis via immunosuppressive actions [30-32]. Cortisol activity has been identified as a prognostic factor in breast and lung cancer $[32,33]$. Depression and low quality of life are also associated with increased production of VEGF, which may stimulate endothelial cell migration, proliferation, and proteolytic activity [34]. DiMatteo et al. found a strong association between depression and medical noncompliance [35], and women with depression who are diagnosed with breast cancer undergo definitive treatment less often and have worse survival outcomes [36].

Some limitations of this study should be considered when interpreting the results. First, the SEER database only provides marital status at the time of diagnosis and does not account for changes in marital status during the follow-up period, which may also influence outcomes. Second, the SEER database lacks details about the quality of marriages (e.g., satisfaction with the relationship, sexual activity), which might be associated with survival in GBC patients. For example, marital distress has long-term immune consequences and enhances the risk of a variety of health problems [37]. Third, and perhaps most important, the SEER database does not provide detailed data regarding chemotherapy, other types of therapy, subsequent therapy, comorbidities, recurrence, or socioeconomic factors.

Despite these potential limitations, our findings demonstrate that marital status is an independent prognostic factor for survival in patients with BTC. Specifically, unmarried patients are at greater risk of cancer-specific mortality. Psychosocial factors may be the main contributors to poorer survival outcomes in unmarried patients; additional social support should therefore be provided for these patients.

\section{Author contributions}

WS and LC conceived of and designed the study. WS and DLM searched databases and collected the data. WS, DLM, and LC analyzed and interpreted the data. WS, DLM, and LC wrote the manuscript. All authors reviewed the final manuscript.

\section{ACKNOWLEDGMENTS}

The authors acknowledge the efforts of the Surveillance, Epidemiology, and End Results (SEER) Program tumor registries in the creation of the SEER database. The interpretation and reporting of these data are the sole responsibility of the authors.

\section{CONFLICTS OF INTEREST}

The authors declare no conflicts of interest.

\section{FUNDING}

None.

\section{REFERENCES}

1. Patel T. Cholangiocarcinoma--controversies and challenges. Nat Rev Gastroenterol Hepatol. 2011; 8:189-200.

2. Vasilieva LE, Papadhimitriou SI, Dourakis SP. Modern diagnostic approaches to cholangiocarcinoma. Hepatobiliary \& pancreatic diseases international. 2012; 11:349-359.

3. Jung KW, Won YJ, Oh CM, Kong HJ, Lee DH, Lee KH. Prediction of Cancer Incidence and Mortality in Korea, 2017. Cancer Res Treat. 2017; 49:306-312.

4. Taylor-Robinson SD, Foster GR, Arora S, Hargreaves S, Thomas HC. Increase in primary liver cancer in the UK, 1979-94. Lancet. 1997; 350:1142-1143.

5. Katanoda K, Hori M, Matsuda T, Shibata A, Nishino Y, Hattori M, Soda M, Ioka A, Sobue T, Nishimoto H. An updated report on the trends in cancer incidence and mortality in Japan, 1958-2013. Japanese journal of clinical oncology. 2015; 45:390-401.

6. Hasegawa S, Ikai I, Fujii H, Hatano E, Shimahara Y. Surgical resection of hilar cholangiocarcinoma: analysis of survival and postoperative complications. World journal of surgery. 2007; 31:1256-1263.

7. Weigt J, Malfertheiner P. Cisplatin plus gemcitabine versus gemcitabine for biliary tract cancer. Expert Rev Gastroenterol Hepatol. 2010; 4:395-397.

8. Wang Y, Li J, Xia Y, Gong R, Wang K, Yan Z, Wan X, Liu G, Wu D, Shi L, Lau W, Wu M, Shen F. Prognostic nomogram for intrahepatic cholangiocarcinoma after partial hepatectomy. Journal of clinical oncology. 2013; 31:1188-1195.

9. Buettner S, van Vugt JLA, Gaspersz MP, Coelen RJS, Roos E, Labeur TA, Margonis GA, Ethun CG, Maithel SK, Poultsides G, Tran T, Idrees K, Isom CA, et al. Survival after resection of perihilar cholangiocarcinoma in patients with lymph node metastases. HPB (Oxford). 2017; 19:735-740.

10. Kaplan RM, Kronick RG. Marital status and longevity in the United States population. J Epidemiol Community Health. 2006; 60:760-765.

11. Hu YR, Goldman N. Mortality differentials by marital status: an international comparison. Demography. 1990; 27:233-250.

12. Wu C, Chen P, Qian JJ, Jin SJ, Yao J, Wang XD, Bai DS, Jiang GQ. Effect of marital status on the survival of patients with hepatocellular carcinoma treated with surgical resection: an analysis of 13,408 patients in the surveillance, epidemiology, and end results (SEER) database. 
Oncotarget. 2016; 7:79442-79452. http://doi.org/10.18632/ oncotarget. 12722 .

13. Aizer AA, Chen MH, McCarthy EP, Mendu ML, Koo S, Wilhite TJ, Graham PL, Choueiri TK, Hoffman KE, Martin NE, Hu JC, Nguyen PL. Marital status and survival in patients with cancer. Journal of clinical oncology. 2013; 31:3869-3876.

14. Zhang W, Wang X, Huang R, Jin K, Zhangyuan G, Yu W, Yin Y, Wang H, Xu Z, Sun B. Prognostic value of marital status on stage at diagnosis in hepatocellular carcinoma. Sci Rep. 2017; 7:41695.

15. Adekolujo OS, Tadisina S, Koduru U, Gernand J, Smith SJ, Kakarala RR. Impact of Marital Status on Tumor Stage at Diagnosis and on Survival in Male Breast Cancer. American journal of men's health. 2017; 11:1190-1199.

16. Qiu M, Yang D, Xu R. Impact of marital status on survival of gastric adenocarcinoma patients: Results from the Surveillance Epidemiology and End Results (SEER) Database. Sci Rep. 2016; 6:21098.

17. Wang XD, Qian JJ, Bai DS, Li ZN, Jiang GQ, Yao J. Marital status independently predicts pancreatic cancer survival in patients treated with surgical resection: an analysis of the SEER database. Oncotarget. 2016; 7:24880-24887. http:// doi.org/10.18632/oncotarget.8467.

18. Cronin KA, Ries LA, Edwards BK. The Surveillance, Epidemiology, and End Results (SEER) Program of the National Cancer Institute. Cancer. 2014; 120 Suppl 23:3755-3757.

19. Osborne C, Ostir GV, Du X, Peek MK, Goodwin JS. The influence of marital status on the stage at diagnosis, treatment, and survival of older women with breast cancer. Breast Cancer Res Treat. 2005; 93:41-47.

20. Nayeri K, Pitaro G, Feldman JG. Marital status and stage at diagnosis in cancer. N Y State J Med. 1992; 92:8-11.

21. Kaiser NC, Hartoonian N, Owen JE. Toward a cancerspecific model of psychological distress: population data from the 2003-2005 National Health Interview Surveys. J Cancer Surviv. 2010; 4:291-302.

22. Baine M, Sahak F, Lin C, Chakraborty S, Lyden E, Batra SK. Marital status and survival in pancreatic cancer patients: a SEER based analysis. PloS one. 2011; 6:e21052.

23. Goldzweig G, Andritsch E, Hubert A, Brenner B, Walach N, Perry S, Baider L. Psychological distress among male patients and male spouses: what do oncologists need to know? Annals of oncology. 2010; 21:877-883.

24. Iwashyna TJ, Christakis NA. Marriage, widowhood, and health-care use. Soc Sci Med. 2003; 57:2137-2147.
25. Haley WE. Family caregivers of elderly patients with cancer: understanding and minimizing the burden of care. J Support Oncol. 2003; 1:25-29.

26. Garssen B, Goodkin K. On the role of immunological factors as mediators between psychosocial factors and cancer progression. Psychiatry Res. 1999; 85:51-61.

27. Sklar LS, Anisman H. Stress and coping factors influence tumor growth. Science. 1979; 205:513-515.

28. Moreno-Smith M, Lutgendorf SK, Sood AK. Impact of stress on cancer metastasis. Future Oncol. 2010; 6:1863-1881.

29. Levy SM, Herberman RB, Whiteside T, Sanzo K, Lee J, Kirkwood J. Perceived social support and tumor estrogen/ progesterone receptor status as predictors of natural killer cell activity in breast cancer patients. Psychosom Med. 1990; 52:73-85.

30. McEwen BS, Biron CA, Brunson KW, Bulloch K, Chambers WH, Dhabhar FS, Goldfarb RH, Kitson RP, Miller AH, Spencer RL, Weiss JM. The role of adrenocorticoids as modulators of immune function in health and disease: neural, endocrine and immune interactions. Brain Res Brain Res Rev. 1997; 23:79-133.

31. Lointier P, Wildrick DM, Boman BM. The effects of steroid hormones on a human colon cancer cell line in vitro. Anticancer research. 1992; 12:1327-1330.

32. Sephton SE, Lush E, Dedert EA, Floyd AR, Rebholz WN, Dhabhar FS, Spiegel D, Salmon P. Diurnal cortisol rhythm as a predictor of lung cancer survival. Brain Behav Immun. 2013; 30:S163-170.

33. Sephton SE, Sapolsky RM, Kraemer HC, Spiegel D. Diurnal cortisol rhythm as a predictor of breast cancer survival. J Natl Cancer Inst. 2000; 92:994-1000.

34. Ferrara N, Davis-Smyth T. The biology of vascular endothelial growth factor. Endocr Rev. 1997; 18:4-25.

35. DiMatteo MR, Lepper HS, Croghan TW. Depression is a risk factor for noncompliance with medical treatment: metaanalysis of the effects of anxiety and depression on patient adherence. Arch Intern Med. 2000; 160:2101-2107.

36. Goodwin JS, Zhang DD, Ostir GV. Effect of depression on diagnosis, treatment, and survival of older women with breast cancer. J Am Geriatr Soc. 2004; 52:106-111.

37. Jaremka LM, Glaser R, Malarkey WB, Kiecolt-Glaser JK. Marital distress prospectively predicts poorer cellular immune function. Psychoneuroendocrinology. 2013; 38:2713-2719. 